\section{For daily hygiene and happiness}

Achieving a healthy and clean mouth will make your patients feel happy.

With your guidance, oral hygiene can be simplified by using the best products for them, in the right way.

To help them choose, recommend TANDEX, because the packaging on its brushes shows Passage Hole Diameter (PHD) and ISO numbers:

- PHD indicates brush size in $\mathrm{mm}$

- ISO is a standard size from $0-8$

- PHD and ISO together form a unique combination, identified by the colour of brush handle.

A simple way to feel good - TANDEX is the premium oral health brand. Discover the full range today.

For more information on Tandex's range of products, visit https://tandex.dk/.

\section{The game-changing COVID-19 antibody test}

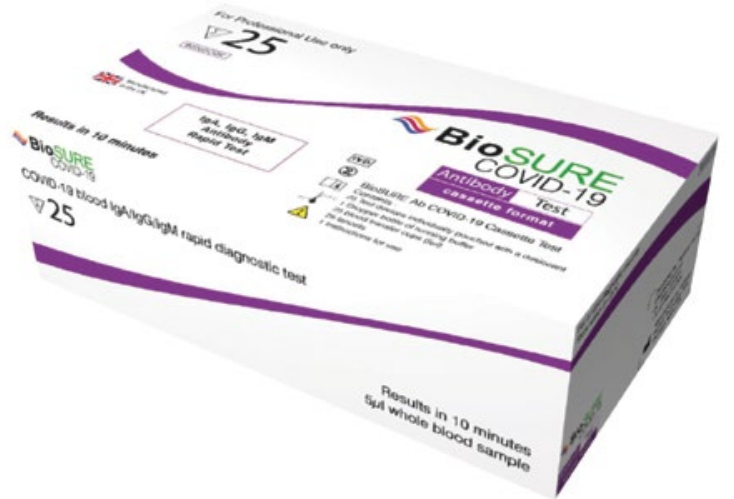

Screening your dental team for COVID-19 is quick and effective with the BioSURE COVID-19 Triple Antibody Rapid Test. It is simple to perform and only requires $5 \mathrm{ul}$ of capillary blood to deliver results in just ten minutes.

Developed and manufactured in the UK, this test comes in a box - priced at $£ 750$ excluding VAT - that contains sufficient product for 25 tests ( $£ 30$ per test). Take full advantage of this game-changing solution with the help of leading oral health specialist, Curaden. The team can support you with:

- High-quality PPE

- Educational resources

- Comprehensive training for your COVID-19 screening staff

- Creating a socially distanced screening area in your practice

- Reporting tools in the form of the BioSURE powered by PocDoc app.

To order, call 01480 862084, email info@curaprox.co.uk or visit www.curaprox.co.uk.

\section{A promise that stands strong}

Colosseum Dental UK is committed to providing a great place to work for all of their clinicians. That's why they make promises to their associate dentists and do everything they can to deliver on each one.

- Colosseum will pay you $1 / 12$ th for the first six months as they know it takes time to settle in

- Excellent working facilities

- The highest standards of clinical governance and expert support

- Access to ongoing CPD

- Mentoring opportunities

- Qualified dental nurses

- Access to a wide range of consumables

- Work with the lab of your choice (DAMAS registered)

- Well-established patient lists

- New Pastelli uniforms

- Equipment repairs fixed in a day.

So, if you're looking for a new position where you will feel valued, listened to, challenged and supported, consider joining Colosseum Dental UK.

For more information about Colosseum Dental, visit www. colosseumdental.co.uk/careers.

\section{Off-screen learning}

We have all spent a lot of time staring at screens recently. Web-based solutions have provided the only means of education, communication and networking throughout the global pandemic. While these have been critical for people's wellbeing and business survival, the time for off-screen learning will be back soon.

The British Dental Conference and Dentistry Show 2021 will present two days of lecture programmes packed full of inspirational content. Internationally-renowned speakers will share their insights and expertise to help colleagues develop their skills and to spark debate about emerging treatment trends.

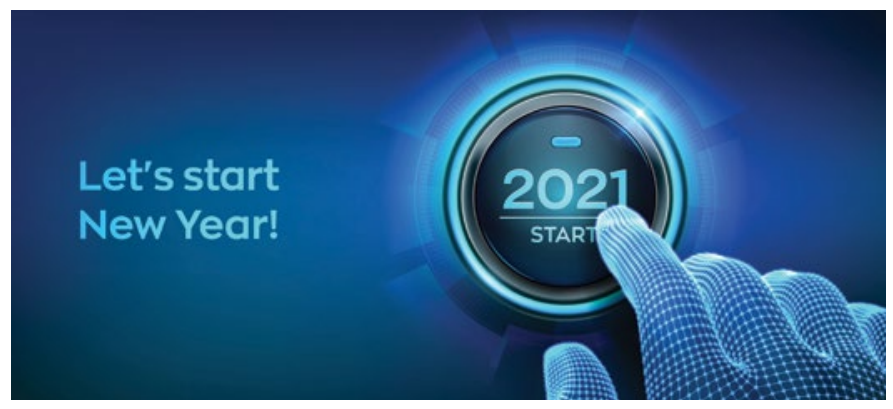

The extensive exhibition will also host hundreds of dental suppliers, manufacturers and training providers, each with exciting announcements and new ideas to help you build a safe and stable future. If you haven't already, get the dates in your diary!

The British Dental Conference and Dentistry Show 2021 will be held on Friday 21 and Saturday 22 May, Birmingham NEC, co-located with DTS.

For more information, visit www.thedentistryshow.co.uk, call 020 73485270 or email dentistry@closerstillmedia.com. 